\title{
Hubungan Motivasi Diri dan Sokongan Sosial Terhadap Kesejahteraan Psikologi Pelajar Universiti
}

\section{(The Relationship between Self-Motivation and Social Support on University Students' Psychological Well-Being)}

\author{
Nur Fatihah Binti Zainuddin1*iD, Faridah Mydin Kutty² \\ 1Fakulti Pendidikan, Universiti Kebangsaan Malaysia (UKM), 43600, Bangi, Selangor, Malaysia. \\ Email: nurfatihah.ayu11@gmail.com \\ ${ }^{2}$ Fakulti Pendidikan, Universiti Kebangsaan Malaysia (UKM), 43600, Bangi, Selangor, Malaysia. \\ Email: fmkfpend@gmail.com
}

\author{
CORRESPONDING \\ AUTHOR (*): \\ Nur Fatihah Binti Zainuddin \\ (nurfatihah.ayu11@gmail.com) \\ KATA KUNCI: \\ Motivasi diri \\ Sokongan sosial \\ Kesejahteraan psikologi \\ KEYWORDS: \\ Self-motivation \\ Social support \\ Psychological well-being

\section{CITATION:} \\ Nur Fatihah Binti Zainuddin \& Faridah \\ Mydin Kutty. (2022). Hubungan Motivasi \\ Diri dan Sokongan Sosial Terhadap \\ Kesejahteraan Psikologi Pelajar Universiti. \\ Malaysian Journal of Social Sciences and \\ Humanities (MJSSH), 7(2), e001308. \\ https://doi.org/10.47405/mjssh.v7i2.1308
}

\begin{abstract}
ABSTRAK
Motivasi diri dan sokongan sosial merupakan salah satu aspek yang perlu dijaga dan diterapkan dalam diri seseorang bagi memenuhi dan memelihara kesejahteraan psikologi diri. Tujuan kajian ini adalah untuk mengenal pasti tahap motivasi diri, sokongan sosial dan kesejahteraan psikologi pelajar serta mengkaji hubungan antara motivasi diri dan sokongan sosial terhadap kesejahteraan psikologi pelajar universiti. Reka bentuk kajian ini adalah menggunakan kuantitatif dengan kaedah tinjauan yang menggunakan soalan soal selidik yang dihuraikan secara deskriptif dan inferensi. Kajian ini dijalankan terhadap 252 pelajar sarjana fakulti pendidikan Universiti Kebangsaan Malaysia (UKM) melalui persampelan rawak mudah. Instrumen yang digunakan dan diadaptasi dalam kajian ini adalah melibatkan Motivated Strategies for Learning Questionnaire (MSLQ) dan Self-Motivation Quiz University Counseling and Consulting Services, University of Minnesota, Quick-Scoring Achievement Motivation Quiz untuk mengukur tahap motivasi diri, manakala Multidimensional Scale of Perceived Social Support (MSPSS) pula adalah untuk tahap sokongan sosial, dan Ryff's Psychological Well-Being Scales (PWB) diukur bagi melihat tahap kesejahteraan pelajar. Hasil dapatan kajian menunjukkan ketiga-tiganya berada pada tahap yang tinggi antara nilaian min 5.06 hingga 5.61. Dapatan menunjukkan terdapat hubungan antara motivasi $\operatorname{diri}(\mathrm{r}=0.576, \mathrm{p}<0.01)$ dan sokongan sosial $(\mathrm{r}=0.495, \mathrm{p}<0.01)$ terhadap kesejahteraan psikologi pelajar universiti. Oleh yang demikian, motivasi diri dan sokongan sosial perlu diberikan perhatian dan diterapkan dalam memperoleh kesejahteraan psikologi bagi para pelajar. Hal ini kerana dengan ada kesejahteraan psikologi dalam diri, mampu membina dan membangun kehidupan yang positif.
\end{abstract}




\begin{abstract}
Self-motivation and social support are two factors that an individual should consider and apply to establish and sustain psychological well-being. The objective of this study was to identify the students' self-motivation, social support, and psychological well-being, as well as the relationship between self-motivation and social support for university students' psychological well-being. The study employs a quantitative survey strategy that utilize questionnaires descriptively. A simple random sampling method was used to recruit 252 undergraduate students from the faculty of education at Universiti Kebangsaan Malaysia (UKM). The instruments utilized were adapted from Motivated Strategies for Learning Questionnaire (MSLQ), and Self-Motivation Quiz University Counseling and Consulting Services, University of Minnesota, Quick-Scoring Achievement Motivation Quiz to measure the level of self-motivation, Multidimensional Scale of Perceived Social Support (MSPSS) measured the level of social support, and Ryff's Psychological Well-Being Scales (PWB) determined the level of students' well-being. The correlation between self-motivation and social support was measured inferentially using Pearson Correlation. The analysis showed that there was a correlation between selfmotivation ( $r=0.576, p<0.01)$ and social support $(r=0.495$, $\mathrm{p}<0.01$ ) on the university students' psychological well-being. Therefore, self-motivation and social support must be emphasized and implemented in sustaining students' psychological well-being. Self-motivation and social support are vital aspects of psychological well-being. This is because psychological well-being enables an individual to construct and develop a positive existence.
\end{abstract}

Sumbangan/Keaslian: Kajian ini memberi sumbangan literatur sedia ada dan yang baru berkaitan dengan kajian hubungan motivasi diri dan sokongan sosial terhadap kesejahteraan psikologi pelajar universiti.

\title{
1. Pengenalan
}

Pada dasarnya, apabila wabak Covid-19 menular, ini kerana akan menyebabkan pelbagai tekanan dan kesan emosi, seperti kekeliruan, kegelisahan, kesedihan serta ketakutan akan kematian. Tekanan adalah berkait rapat dengan isu kesihatan mental. Isu tekanan dalam kalangan pelajar universiti bukan sesuatu perkara yang baru dan ia mencetuskan kebimbangan pelbagai pihak (Muhammad Wafi \& Sharifah, 2020) Tekanan menyebabkan seseorang pelajar tidak dapat menikmati kehidupan yang baik (Diani, Amirah \& Farhana, 2017) dan mengakibatkan gangguan emosi yang memberi kesan kepada diri seseorang. Dasar Kesihatan Mental Negara (2014) pula mentakrifkan tekanan boleh mengakibatkan kemampuan individu, kelompok dan persekitaran untuk berinteraksi antara satu sama terjejas dan kesejahteraan subjektif secara optimum dan penggunaan keupayaan kognitif, afektif dan psikomotor dalam tindakan seharian kurang memberangsangkan.

Wabak COVID-19 telah mengakibatkan banyak perkara telah terjejas dalam melaksanakan tugas sebagai seorang pelajar mahupun berhadapan dengan sesi pengajaran dan pembelajaran. Sesi pengajaran tidak dapat dijalankan dengan sempurna 
dan interaksi antara pensyarah dengan pelajar tidak dapat dilaksanakan secara dua hala (Zarien et al., 2019). Sejak kebelakangan ini, isu tekanan yang dialami oleh pelajar universiti amat membimbangkan dan ia bukanlah sesuatu perkara yang baru. Tekanan adalah fenomena yang sering ditafsirkan sebagai ancaman besar terhadap kesihatan mental (Awang, 2016). Isu kesihatan mental kebiasaannya meningkat dalam kalangan pelajar universiti yang memberi impak besar terhadap peringkat kehidupan mereka (Wenjuan et al., 2020; Bruffaerts et al., 2018). Pelajar prasiswazah dan pascasiswazah di universiti berada dalam keadaan yang mana gangguan berkaitan dengan tekanan adalah suatu kebiasaan (Ribeiro et al., 2018).

Tekanan yang negatif memberi impak yang kurang baik termasuk mental, emosi dan kesihatan (Durham Insight, 2014). Pelajar turut terkesan apabila wabak COVID-19, yang terjadi mengancam nyawa pada masa ini, dan telah mengubah corak serta gaya hidup masyarakat sehingga mempengaruhi kesejahteraan psikologi seseorang (Abdul Rashid et al., 2020). Pengajian tinggi sangat memberi tekanan kepada pelajar kerana mereka perlu melalui proses penyesuaian persekitaran pendidikan dan persekitaran sosial yang baru (Habeeb, 2020; Ramachandiran \& Dhanapal, 2018). Walaupun pelajar universiti dianggap sebagai generasi yang bernasib baik kerana berjaya menempatkan diri di universiti, namun realitinya mereka merupakan individu yang melalui tekanan berterusan kerana perubahan hidup sepanjang tempoh pengajian (Ganesan et al., 2018). Menurut Yikealo (2018), pelajar universiti mengalami pelbagai kesukaran seperti penyesuaian pendidikan, sosial, persekitaran, dan psikologi dalam suasana kampus baru yang boleh mempengaruhi kesejahteraan psikososial dan hasil pembelajaran mereka. Salam et al. (2013) menyatakan bahawa tekanan dalam kalangan pelajar universiti banyak dikaitkan dengan masalah kewangan, masalah hubungan, dan masalah akademik.

Kajian ini dijalankan untuk meninjau motivasi diri pelajar dan sokongan terhadap kesejahteraan psikologi sewaktu berhadapan dengan pandemik wabak COVID-19 yang mengakibatkan berlakunya penutupan semua sektor pendidikan dan hanya mampu menjalankan sesi pembelajaran secara dalam talian sahaja. Pelajar Sarjana juga turut terkesan apabila mereka perlu menjalani sesi pengajaran dan pembelajaran, penyeliaan tesis, pemantauan, penilaian dan peperiksaan serta perbincangan dengan rakan-rakan di alam maya.

Oleh yang demikian tujuan kajian ini adalah untuk mengkaji hubungan antara motivasi diri dan sokongan terhadap kesejahteraan psikologi pelajar universiti. Antara objektif kajian yang perlu dicapai adalah seperti berikut:

i. Mengenal pasti tahap motivasi diri, tahap sokongan sosial dan tahap kesejahteraan psikologi pelajar universiti.

ii. Mengkaji hubungan antara motivasi diri dan sokongan sosial terhadap kesejahteraan psikologi pelajar universiti.

Penulisan ini menjelaskan beberapa bahagian, antaranya adalah pengenalan berkaitan dengan kajian yang dijalankan. Selain itu adalah dengan menjelaskan sorotan literatur yang diperolehi. Dapatan data juga turut dikemukan berserta metod kajian. Dan seterusnya adalah perbincangan dan diakhiri dengan kesimpulan.

\section{Sorotan Literatur}

Pelaksanaan Perintah Kawalan Pergerakan ini telah memberikan kesan pelbagai terhadap masyarakat, tidak kira dalam apa jua lapangan sektor mereka. Dalam konteks 
pendidikan misalnya, rentetan daripada penutupan pusat pengajian telah menuntut kepada pelaksanaan pembelajaran secara dalam talian (Norhana, 2020). Tidak sekadar di Malaysia, malahan ianya menjadi alternatif pilihan bagi sistem pendidikan di negara yang terjejas dengan wabak ini (Moawad, 2020). Demikian, medium pembelajaran secara dalam talian telah diketengahkan secara meluas bagi memastikan kesinambungan pembelajaran sedia ada. Walaupun medium ini bukanlah suatu yang asing bagi beberapa aliran pendidikan di negara maju, tetapi bagi segelintir aliran pendidikan yang tidak sinonim dengan medium sebegini sudah pasti akan membangkit beberapa permasalahan terhadap keupayaan berurusan dengan teknologi sedia ada

Irshad et al. (2015) menyatakan bahawa kebanyakan pelajar universiti mengalami tekanan dari segi beban kerja, keluarga, kawan dan pensyarah untuk mengekalkan hasil kerja yang baik dan menyelesaikan tugasan tepat pada masanya tanpa gagal. Hal ini mengesahkan bahawa kehidupan di universiti merupakan tekanan dalam kehidupan pelajar (Thawabieh \& Qaisy, 2012). Ramachandiran dan Dhanapal (2018) pula menyatakan bahawa pelajar yang mengalami tekanan disebabkan oleh masalah keluarga, keperluan biasiswa, beban kewangan, persaingan dalam kelas, peperiksaan, pengurusan masa, dan tekanan yang berkaitan dengan kursus. Hanna et al. (2018) menyatakan bahawa pilihan kerjaya dan peluang pekerjaan mendorong kepada tekanan dalam kalangan pelajar. Yikealo (2018) juga turut menyatakan bahawa pelajar kebiasaannya mengalami tekanan disebabkan oleh keperluan untuk memastikan kelangsungan akademik dan persediaan untuk melanjutkan kerjaya mereka.

Irma et al. (2020) menyatakan tidak sukar untuk mereka menggunakan pelantar pembelajaran dalam talian dan ini merupakan satu cabaran kepada semua dalam sektor pendidikan dan akademik. Namun masih pelajar di universiti juga mengalami motivasi yang meleset apabila kurangnya sokongan sosial daripada keluarga dan semangat untuk melaksanakan pembelajaran dalam talian. Hal ini menyebabkan motivasi pelajar akan berada pada tahap rendah dan sukar. Nur Syazana dan Mohd Nasir (2020) menyatakan motivasi belajar memberi implikasi terhadap pelajar dalam memiliki strategi yang bersesuaian dalam aktiviti pembelajaran dan memupuk dorongan dalam usaha yang dilaksanakan sepanjang pengajian.

Kajian Zaiton (2020) menyatakan kesan wabak COVID-19 menjejaskan sistem pendidikan. PKP turut menyebabkan institusi pengajian tinggi terpaksa ditutup. Penutupan tersebut telah menyebabkan ramai pelajar terkandas di kediaman dalam dan luar kampus. Impaknya dapat dilihat apabila tahap kesejahteraan psikologi dan kawalan diri menjadi semakin merosot. Dapatan kajian mendapati bahawa tidak terdapat perbezaan tahap kesejahteraan psikologi pelajar yang tinggal di dalam dan di luar kampus dalam tempoh PKP. Hal ini disebabkan oleh pelajar masih tertekan walaupun berada di kediaman yang berbeza. Hasil perbincangan menyatakan bahawa antara penyebab tahap kesejahteraan psikologi pelajar semakin merosot kerana lambakan tugasan yang diberikan oleh pensyarahnya dan tidak mendapat sokongan moral yang sewajarnya

\subsection{Motivasi Diri dan Sokongan Sosial}

Lawten (1991) menyatakan bahawa kesejahteraan psikologi merupakan suatu asas untuk mendapat kualiti kehidupan, ini kerana ianya boleh bertindak dalam mendapatkan kualiti kehidupan yang dilihat pada aspek kehidupan seharian. 
Menurut Oemar Hamalik (2002), motivasi merupakan suatu perkara yang mendorong kepada sesuatu perbuatan serta mengarahkan perbuatan dalam mendapatkan pencapaian yang diinginkan. Motivasi juga dianggap sebagai suatu perkaitan dengan keperluan individu yang mempunyai dorongan untuk memenuhi kehendak diri. Motivasi juga dapat dijelaskan sebagai interaksi antara tingkah laku, persekitaran, kognisi, dan faktor peribadi (Yuan Kong, 2009). Menurut Maryam (2016), motivasi merupakan perubahan kekuatan dalam diri seseorang yang datang melalui dorongan dalaman dari diri seseorang untuk mencapai tujuan. Dorongan dan reaksi usaha yang disebabkan keperluan ini adalah bertujuan untuk bertindak dalam meningkatkan aspek kehidupan. Melalui ini dapat dilihat bahawa motivasi adalah suatu perihal yang membimbing individu untuk terus berusaha dan mendorong dalam mencapai hasil pembelajaran yang baik. Dari ini dapat dilihat bahawa motivasi adalah sumber kekuatan untuk menjalankan aktiviti untuk mencapai tujuan hidup. Motivasi menjadi kekuatan dalam situasi yang kompleks dan mempersiapkan individu. Motivasi adalah suatu perasaan yang mendorong kekuatan diri seseorang untuk meneruskan sesuatu perkara dengan sebaiknya.

Sokongan sosial pula didefinisikan sebagai hubungan interpersonal di antara satu sama lain dan sokongan yang diberikan oleh institusi sosial bertujuan dalam memberikan kesejahteraan individu (Costello, Pickens \& Fenton, 2001). Manakala menurut Amna Emda (2017) pula menyatakan motivasi adalah suatu usaha untuk menyediakan dan menyiapkan keadaan yang tertentu sehingga seseorang itu teringin untuk melakukan sesuatu perkara. Selain itu, motivasi juga berasal dari kata motif sebagai daya penggerak yang ada pada diri seseorang untuk melakukan aktiviti tertentu dalam mencapai sesuatu kehendak. Menurut Azlina et al., (2020) pula menyatakan bahawa sokongan sosial merujuk kepada dua kekuatan iaitu dari segi fizikal dan psikologi untuk membantu seseorang mengatasi tekanan. Oleh yang demikian, sokongan sosial ialah suatu perhubungan yang melibatkan diri dengan insan yang lain dalam menghadapi sesuatu permasalahan atau tekanan.

\section{Metod Kajian}

\subsection{Reka Bentuk Kajian}

Kajian ini menggunakan kaedah kajian kuantitatif yang berbentuk tinjauan. Kaedah kuantitatif merupakan kaedah pengumpulan data kajian menggunakan edaran soal selidik yang mempunyai skala sebagai pengukuran hasil dapatan data kajian. Kajian ini melibatkan kaedah pengumpulan data dan penganalisisan data yang melibatkan pengumpulan, analisis, dan interpretasi data (Noraini, 2010). Kaedah kuantitatif menekankan pengukuran objektif dan analisis secara statistik atau numerikal data yang dikumpulkan melalui tinjauan pendapat atau soal selidik. Kajian ini menggunakan pengedaran soal selidik secara google form secara talian dengan teknik persampelan Convenience Sampling. Penyelidikan kaedah kuantitatif ini dengan mengedar soal selidik secara dalam talian kepada pelajar sarjana yang terlibat dengan kajian ini.

\subsection{Sampel Kajian}

Pemilihan responden dalam kajian ini adalah melibatkan yang terdiri daripada pelajarpelajar dari program dan kursus pendidikan Ijazah Sarjana dan Doktor Falsafah (PhD) dari Fakulti Pendidikan di Universiti Kebangsaan Malaysia. Persampelan kajian ini dilakukan secara rawak mudah dengan mengambil kira nilai populasi dan persampelan berdasarkan Krejcie dan Morgan (1970). Melalui data yang diperoleh dari pihak Fakulti 
Pendidikan Universiti Kebangsaan Malaysia, pengkaji mendapati populasi bagi pelajar siswazah adalah seramai $\mathrm{N}=663$ orang pelajar. Dalam menentukan sampel kajian berdasarkan populasi yang diperoleh sampel saiz dalam kajian ini adalah $\mathrm{S}=240$ orang. Penentuan sampel ini adalah berdasarkan Krejcie dan Morgan (1970) dalam penentuan sampel saiz. Oleh itu kajian ini dilaksanakan dengan persampelan bagi kajian ini adalah seramai 252 orang pelajar sarjana.

\subsection{Instrumen Kajian}

Kajian ini menggunakan kaedah soal selidik agar pengkaji dapat memperkayakan hasil dapatan kajian daripada responden dengan lebih mudah dan praktikal bagi mendapatkan maklumat yang tepat dan berkesan. Soal selidik ini dibangunkan dari kaedah adapt and adopt kajian primer atau kajian lepas sebagai asas kepada instrumen kajian yang digunakan. Instrumen ini dilakukan kesahan pakar dan dilihat dari kebolehpercayaan item dengan menganalisis alpha cronbach atau menjalankan kajian rintis.

Seterusnya soal selidik ini dimurnikan dan disesuaikan dengan lengkap bagi memudahkan responden atau pelajar sarjana menjawab dengan lancar. Secara khususnya, Soal selidik yang disusun dalam kajian ini mengandungi empat bahagian utama yang melibatkan soalan demografi dan menggunakan soalan berbentuk tujuh skala likert. Bahagian A membincangkan item demografi. Bahagian A terdiri daripada bahagian demografi yang mempunyai maklumat latar belakang sampel kajian yang dibina untuk mendapatkan maklum balas seperti jantina, umur dan peringkat pengajian. Maklumat demografi ini diperlukan untuk mendapatkan hasil analisis data secara meluas (Ghazali dan Sufean, 2018).

Bahagian B, C dan D mengandungi item yang berbentuk skala tujuh likert. Soal selidik ini merupakan hasil adaptasi dan ubahsuai dari soal selidik yang asal. Pada bahagian B soal selidik telah diubah suai dengan merujuk kepada Motivated Strategies for Learning Questionnaire (MSLQ) oleh Pintrich et al., (1990) dan Self-Motivation Quiz University Counseling and Consulting Services, University of Minnesota, Quick-Scoring Achievement Motivation Quiz oleh Cody (2014). Item soal selidik ini bertujuan dalam mendapatkan data berkaitan dengan tahap motivasi diri bagi pelajar universiti yang ingin dikaji.

Bagi bahagian C pula adalah untuk melihat tahap sokongan sosial para pelajar universiti. Dalam bahagian ini soal selidik diadaptasi dengan merujuk pada instrumen soal selidik Multidimensional Scale Of Perceived Social Support (MSPSS) yang mengandungi 12 item soalan. Soal selidik ini juga mengandungi soalan yang berkaitan kesejahteraan psikologi seseorang. Kesejahteraan Psikologi diadaptasi dari set soal selidik ini pula merujuk pada Ryff's Psychological Well-Being Scales (PWB) oleh Ryff (1989).

\subsection{Kebolehpercayaan Instrumen Kajian}

Kebolehpercayaan set soal selidik dapat diperhatikan oleh nilai pekali kebolehpercayaan Alfa Cronbach, seperti yang ditunjukkan dalam Jadual 1 di bawah. Kebolehpercayaan ini dianalisis melalui kajian rintis yang dilakukan pada 36 orang pelajar peringkat sarjana muda dan sarjana di Universiti Kebangsaan Malaysia. Hasil analisis mendapati bahawa keseluruhan pekali Alpha Cronbach dari 51 item dalam kajian ini adalah 0.961 . Seterusnya, nilai pekali Alfa Cronbach untuk setiap kategori adalah antara 0.834 dan 0.948 nilai indeks. Kategori ini terbahagi kepada tiga bahagian iaitu motivasi diri (0.948) yang mempunyai 20 item, sokongan sosial (0.936) yang mempunyai 12 item dan yang 
terakhir adalah kesejahteraan psikologi (0.834) yang mempunyai 18 item. Nilai Alfa secara keseluruhan dan berdasarkan kategori nilai $0.834,0.936$ dan 0.948 adalah nilai kebolehpercayaan yang diterima oleh para sarjana (Mohd Majid, 2005).

Jadual 1: Nilai Pekali Kebolehpercayaan Alfa Cronbach Item

\begin{tabular}{lll}
\hline Kategori & Nilai Alpha Cronbach & Bilangan Item \\
\hline Motivasi Diri & 0.948 & 20 item \\
Sokongan Sosial & 0.936 & 12 item \\
Kesejahteraan Psikologi & 0.834 & 18 item \\
Keseluruhan & 0.961 & 50 item \\
\hline
\end{tabular}

\section{Hasil Kajian}

\subsection{Profil Demografi Responden}

Jadual 2 merujuk kepada maklumat latar belakang responden kajian yang terdiri daripada 252 orang pelajar. Responden mengikut jantina yang terlibat dalam kajian ini adalah seramai 198 orang atau 78.6 peratus adalah terdiri daripada pelajar perempuan, manakala seramai 54 orang atau 21.4 peratus lagi terdiri daripada pelajar lelaki. Ini menunjukkan bahawa jumlah responden dalam kalangan pelajar perempuan melebihi jumlah pelajar lelaki dalam kajian ini.

Jadual 2: Maklumat Latar Belakang Responden

\begin{tabular}{llll}
\hline Demografi & Faktor & Bilangan & Peratus \\
\hline Jantina & Perempuan & 198 & $78.6 \%$ \\
Umur & Lelaki & 54 & $21.4 \%$ \\
& $21-25$ tahun & 59 & $23.4 \%$ \\
& $26-30$ tahun & 83 & $32.9 \%$ \\
& $31-35$ tahun & 35 & $13.9 \%$ \\
Bangsa & $36-40$ tahun & 34 & $13.5 \%$ \\
& 40 tahun ke atas & 41 & $16.3 \%$ \\
& Melayu & 223 & $88.5 \%$ \\
& India & 9 & $3.6 \%$ \\
& Cina & 8 & $3.2 \%$ \\
\hline
\end{tabular}

Seterusnya, pengkaji meneliti profil pelajar mengikut umur pula menunjukkan kumpulan umur yang paling banyak yang ditunjukkan adalah berada dalam kumpulan umur $26-30$ tahun iaitu sebanyak 32.9\% (83 orang). Diikuti dengan kumpulan umur 21 - 25 tahun iaitu sebanyak $23.4 \%$ (59 orang). Seterusnya kumpulan umur 41 tahun ke atas iaitu sebanyak 16.3\% (41 orang), kumpulan umur 31 - 35 tahun iaitu sebanyak 13.9\% (35 orang) dan terakhir kumpulan umur 36 - 40 tahun iaitu sebanyak 13.5\% (34 orang).

Merujuk kepada Jadual 2 di atas, dapat dilihat bahawa majoriti bangsa responden dalam kajian ini adalah terdiri daripada bangsa Melayu iaitu seramai 223 orang (88.5\%). Diikuti dengan seramai 12 orang (4.8\%) lain-lain bangsa, 9 orang (3.6\%) berbangsa India dan 8 orang $(3.2 \%)$ berbangsa Cina. 


\subsection{Tahap Motivasi Diri, Sokongan Sosial dan Kesejahteraan Psikologi}

Analisis ini menggunakan metod deskriptif secara peratusan dan interpretasi min. Bagi menentukan tahap ukuran objektif adalah melalui dengan nilai interpretasi skor min seperti Jadual 3 di bawah:

Jadual 3: Interpretasi Skor Min Likert 7 Mata

\begin{tabular}{ll}
\hline Skala Min & Tahap Interpretasi \\
\hline $\mathbf{1 . 0 0 - 3 . 0 0}$ & Rendah \\
$\mathbf{3 . 0 1}-\mathbf{5 . 0 0}$ & Sederhana \\
$\mathbf{5 . 0 1 - 7 . 0 0}$ & Tinggi \\
\hline
\end{tabular}

Sumber: Nik Mohd (2004)

Jadual 4 di bawah menunjukkan min dan sisihan piawai kepada tiga kategori iaitu motivasi diri, sokongan sosial dan kesejahteraan psikologi bagi pelajar universiti bagi melihat tahap tinggi atau rendah sesuatu dapatan. Dapatan data menunjukkan motivasi diri mendapati $(\mathrm{min}=5.29, \mathrm{SP}=0.746)$ yang diukur oleh 20 item. Seterusnya, sokongan sosial pula $(\min =5.61, \mathrm{SP}=0.927)$ diukur pada 12 item. Manakala bagi tahap kesejahteraan psikologi pelajar pula menunjukkan $(\min =5.06, \mathrm{SP}=0.701)$ diukur oleh 8 item. Secara keseluruhannya menunjukkan bahawa skor tahap bagi ketiga-tiga kategori ini berada pada tahap yang tinggi dalam kalangan pelajar universiti.

Jadual 4: Min dan Sisihan Piawai Tahap Tiga Kategori

\begin{tabular}{llll} 
Kategori & Min & $\begin{array}{l}\text { Sisihan } \\
\text { Piawai }\end{array}$ & Tahap \\
\hline Motivasi Diri & 5.29 & 0.746 & Tinggi \\
Sokongan Sosial & 5.61 & 0.927 & Tinggi \\
Kesejahteraan Psikologi & 5.06 & 0.701 & Tinggi \\
\hline Keseluruhan & Tinggi & & \\
\hline
\end{tabular}

\subsection{Hubungan Antara Motivasi Diri dan Sokongan Sosial Dengan Kesejahteraan Psikologi}

Kekuatan hubungan antara pemboleh ubah dapat dinilai mengikut tafsiran pekali korelasi oleh Cohen (1998) dan nilai pekali r, seperti yang ditunjukkan dalam Jadual 5. Pekali kolerasi, $\mathrm{r}$ dapat dilihat kekuatannya dari 0.10 hingga 0.29 yang menunjukkan hubungan yang lemah. Manakala, dari 0.30 hingga 0.49 pula menunjukkan kekuatan yang sederhana. Seterusnya yang terakhir, dari 0.5 hingga 1.0 menunjukkan hubungan yang kuat.

Jadual 5: Jadual Interpretasi Pekali Korelasi

\begin{tabular}{ll} 
Pekali Korelasi,r & Kekuatan Hubungan \\
\hline 0.10 hingga 0.29 & lemah \\
0.30 hingga 0.49 & sederhana \\
0.5 hingga 1.0 & kuat \\
\hline
\end{tabular}

Berdasarkan kekuatan yang dilihat oleh pekali korelasi di Jadual 5 atas menunjukkan hubungan antara motivasi diri dan sokongan sosial terhadap kesejahteraan psikologi pelajar berada pada kekuatan hubungan yang kuat. Hal ini dapat dilihat pada Jadual 6 di bawah menunjukkan hubungan motivasi diri dengan kesejahteraan psikologi pelajar 
mempunyai hubungan $(\mathrm{r}=0.576, \mathrm{p}<0.01)$. Manakala hubungan antara sokongan sosial dengan kesejahteraan psikologi pelajar pula berada pada $(r=0.495, p<0.01)$. Kajian ini menunjukkan mempunyai hubungan signifikan antara motivasi diri dan sokongan sosial terhadap kesejahteraan psikologi pelajar universiti.

\section{Jadual 6: Hubungan Antara Motivasi Diri dan Sokongan Sosial Dengan Kesejahteraan Psikologi Pelajar}

\begin{tabular}{lll}
\hline \multirow{2}{*}{ Kategori } & \multicolumn{2}{l}{ Kesejahteraan Psikologi Pelajar } \\
\cline { 2 - 3 } Motivasi Diri & Pekali r & Sig \\
Sokongan Sosial & 0.576 & 0.00 \\
\hline & 0.495 & 0.00 \\
\hline
\end{tabular}

$* * \mathrm{p}<0.01$

\section{Perbincangan Kajian}

Kajian ini bertujuan untuk mengkaji tahap motivasi diri, tahap sokongan sosial dan tahap kesejahteraan psikologi dan hubungan antara motivasi diri dan sokongan sosial terhadap kesejahteraan psikologi pelajar universiti. Mohd Izani (2020) dan Firdaus (2020), telah menjalankan kajian yang bertujuan untuk mengenal pasti tahap kesejahteraan pelajar khususnya di institusi pengajian tinggi. Dapatan kajian in menunjukkan bahawa dipengaruhi oleh pandemik Covid-19 melalui pertama, penangguhan kuliah yang lama bermula 13 April 2020 hingga 8 Jun 2020. Selain itu, pelajar universiti turut diasak dengan penyebaran berita palsu yang berleluasa di sosial media. Hal ini kerana pelajar yang mengalami kegelisahan ringan, sederhana dan teruk tidak tinggal di bersama keluarga mereka semasa wabak berlaku.

Tahap bagi pemboleh ubah kajian iaitu motivasi diri, sokongan sosial serta kesejahteraan psikologi berada pada tahap yang tinggi. Hal ini dapat dilihat bahawa ketiga-tiganya mempunyai hubung kait dalam memperoleh kesejahteraan psikologi para pelajar. Motivasi diri merupakan suatu yang utama dalam meningkatkan dan meneruskan semangat seseorang. Dengan adanya motivasi diri mampu menguatkan diri dalam menghadapi apa jua rintangan dan kesusahan. Apabila seseorang pelajar mampu untuk menepis rintangan dan permasalahan yang datang, pelajar tersebut juga mampu mengawal diri agar sentiasa berada dalam kesejahteraan diri yang baik. Oleh yang demikian, motivasi diri merupakan suatu perkara yang perlu dipupuk pada diri agar menjadi banteng dalam memelihara kesejahteraan diri.

Dalam memelihara motivasi diri, seseorang pelajar juga memerlukan keperluan sokongan sosial sebagai pendorong serta kekuatan untuk terus melakukan sesuatu perkara tambahan pula dalam belajar. Menurut Nurul Hudani et al. (2017) menyatakan bahawa keperluan sokongan sosial ini membolehkan individu mencapai matlamat, memenuhi keperluan, dan mencapai kesejahteraan. Menurutnya lagi, realiti sokongan sosial juga dapat membantu individu mengatasi masalah kesihatan dengan lebih baik, meningkatkan rasa kekitaan, tujuan serta harga diri dan merangsang kesejahteraan yang positif. Dengan dorongan yang terjadi, mampu untuk seseorang memelihara kesejahteraan diri dengan lebih baik dan tenang.

Oleh yang demikian, hubungan antara motivasi diri dan sokongan sosial terhadap kesejahteraan psikologi jelas dilihatkan secara signifikannya. Motivasi diri dan sokongan sosial menjadi peranan dan sumber dalam memperoleh kesejahteraan diri. Justeru, 
diharapkan motivasi diri dan sokongan sosial ini sering mendapat perhatian dan menjadi suatu tindakan dalam memperoleh kesejahteraan diri pelajar. Hal ini kerana pentingnya kesejahteraan psikologi pelajar, agar sentiasa berada dalam keadaan baik untuk bertindak dan belajar. Tanpa adanya kesejahteraan diri, akan membuatkan seseorang tertekan dan bertindak diluar kawalan yang mungkin menjejaskan atau merosakkan sesuatu matlamat pembelajaran sebagai seorang pelajar mahupun kehidupan.

\subsection{Tahap Motivasi Diri Pelajar}

Motivasi diri merupakan suatu penekanan yang perlu diterapkan dalam diri seseorang begitu juga dalam kalangan pelajar. Dalam kajian ini, motivasi dilihat sebagai suatu aspek yang perlu dipelihara dalam mengekalkan dan meningkatkan kesejahteraan psikologi. Tahap motivasi diri dalam kajian ini melibatkan kepada dua dimensi iaitu nilai diri serta tugasan dan keyakinan diri. Melalui hasil dapatan menunjukkan bahawa skor min bagi motivasi diri pelajar adalah 5.29 berada pada tahap yang tinggi. Nilaian min bagi kedua dimensi adalah 5.21 dan 5.37. Hasil kajian menunjukkan kesemua 20 bilangan item tersebut mempunyai skor yang tinggi. Perkara ini selaras dengan kajian Mohd Dahlan dan Ida (2020) menyatakan bahawa motivasi amat penting bagi seseorang untuk memperoleh kesejahteraan psikologi yang baik.

\subsection{Tahap Sokongan Sosial Pelajar}

Hasil dalam kajian bagi tahap sokongan sosial $(\min =5.61, \mathrm{SP}=0.927)$ mendapati berada pada tahan yang tinggi dalam kalangan pelajar universiti. Tahap sokongan sosial pelajar diukur oleh tiga dimensi iaitu keluarga, rakan dan kenalan istimewa. Dapatan menunjukkan dimensi sokongan sosial pelajar iaitu keluarga $(\min =5.69, \mathrm{SP}=1.070)$, rakan $(\min =5.51, \mathrm{SP}=1.006)$ dan kenalan istimewa $(\min =5.63, \mathrm{SP}=1.099)$ adalah berada pada tahap yang tinggi. Dalam dapatan menunjukkan bahawa sokongan sosial dari kenalan istimewa atau juga dikenali sebagai kawan rapat mendapat tahap nilaian yang tertinggi. Hal ini kerana menurut Zurko (2011) menyatakan bahawa kawan rapat memberikan sokongan sosial pada setiap tahap dan perkembangan semasa remaja. Kewujudan sokongan sosial daripada kawan rapat bukan sahaja dapat mengurangkan keresahan remaja di dalam situasi yang sukar malah dapat meningkatkan keyakinan diri dan kesejahteraan (Ciaviano, 2008).

Secara ringkasnya, dapatan memberi pengetahuan bahawa sokongan sosial merupakan suatu penerapan yang positif dalam meningkatkan kesejahteraan psikologi seseorang. Hal ini selari dengan Noraini, Nur Saadah dan Ezarina, (2019) yang menyatakan bahawa sokongan sosial yang mencukupi cenderung untuk berdaya tahan dan juga mencapai tahap kesejahteraan yang tinggi.

\subsection{Tahap Kesejahteraan Psikologi Pelajar}

Secara keseluruhannya nilaian tahap kesejahteraan psikologi dalam kalangan pelajar universiti adalah berada pada tahap yang tinggi ( $\min =5.06, \mathrm{SP}=0.701)$. Dalam mengenal pasti tahap kesejahteraan psikologi pelajar, kajian diukur dengan enam dimensi iaitu autonomi, kehidupan sekitar, perkembangan peribadi, hubungan positif, tujuan dalam hidup dan penerimaan diri sendiri. Dalam pembahagian enam dimensi ini terdapat empat dimensi yang berada pada tahap yang tinggi, manakala dua lagi dimensi lagi berada pada tahap yang sederhana. Empat dimensi yang memperoleh tahap tinggi ialah kehidupan sekitar (5.15), perkembangan peribadi (5.49), hubungan positif (5.03) dan penerimaan 
diri sendiri (5.08). Seterusnya, pada tahap sederhana ialah mewakili dimensi autonomi (4.80) dan tujuan dalam hidup (4.82).

Dimensi autonomi dan tujuan hidup merupakan dimensi yang melibatkan diri dalam membuat keputusan, menentu dan menilai diri. Kajian ini menunjukkan bahawa individu ini mampu untuk berdikari dan tidak memerlukan orang lain untuk membuat keputusan penting dalam kehidupan. Mempunyai kemahuan untuk mencuba dan mempunyai kemahiran daya tindak dalam menangani tekanan dalam kehidupan juga merupakan tindakan yang berada dalam dimensi ini. Ciri-ciri autonomi ini digunakan untuk memberi pedoman dan membina landasan untuk mereka bergerak ke tahap yang lebih tinggi dalam aliran mencapai keterampilan dan integrasi kematangan (Othman, 2000).

\subsection{Hubungan Antara Motivasi Diri dan Sokongan Sosial Terhadap Kesejahteraan Psikologi}

Kajian ini adalah bertujuan untuk mengenal pasti hubungan antara motivasi diri dan sokongan sosial terhadap kesejahteraan psikologi bagi pelajar universiti. Hasil dapatan menunjukkan keputusan yang signifikan antara kedua hubungan antara motivasi diri dan sokongan sosial terhadap kesejahteraan psikologi pelajar. Keputusan pengujian hipotesis menghasilkan dua dapatan penting. Pertama, motivasi diri $(r=0.576, p<0.01)$ mempunyai hubungan yang signifikan dengan kesejahteraan psikologi pelajar. Kedua, sokongan sosial $(r=0.495, \mathrm{p}<0.01)$ mempunyai hubungan yang signifikan dengan kesejahteraan psikologi pelajar. Dengan ini dapat dirumuskan bahawa motivasi diri dan sokongan sosial mempunyai hubungannya dalam memelihara dan meningkatkan kesejahteraan psikologi pelajar. Hal ini turut selaras dengan kajian Mohd Dahlan dan Ida (2020) menyatakan bahawa mereka yang menerima banyak sokongan dan motivasi dari dalam atau luar boleh memberi kesejahteraan psikologi yang positif dalam prestasi kesejahteraan psikologi mereka (Mohd Dahlan \& Ida, 2020).

\section{Kesimpulan}

Dapatan dalam kajian ini menyatakan motivasi diri dan sokongan sosial mempunyai hubungan dengan kesejahteraan psikologi. Hal ini menunjukkan, motivasi diri dan sokongan sosial merupakan suatu perkara yang perlu diambil berat dalam memelihara kesejahteraan psikologi. Pemeliharaan kesejahteraan psikologi ini mampu memberi keamanan dan bimbingan yang positif dalam diri seseorang serta seluruh kehidupan. Secara kesimpulannya diharapkan dapatan kajian mengenai motivasi diri dan sokongan sosial terhadap kesejahteraan psikologi dapat membantu serta memberi manfaat dan kebaikan dalam kalangan masyarakat, institusi pengajian dan pelajar. Melalui kajian ini juga diharapkan perkembangan pendidikan dapat ditingkatkan dan dipelihara sebaiknya dengan mutu yang tinggi dan berkualiti. Hal ini juga dapat memberi dorongan kepada pihak Institusi Pengajian Tinggi dalam memberi penerapan yang baik untuk memelihara kesejahteraan psikologi. Kajian ini juga dapat membuktikan dan memberi kesedaran akan kepentingan motivasi diri dan sokongan sosial dalam mengekalkan kesejahteraan psikologi yang positif. 


\section{Penghargaan (Acknowledgement)}

Terima kasih diucapkan kepada penyelia yang memberi tunjuk ajar dalam menyiapkan kajian dan penulisan artikel serta responden yang memberi kerjasama dalam menjayakan kajian ini.

\section{Kewangan (Funding)}

Kajian dan penerbitan artikel ini tiada sebarang tajaan atau bantuan kewangan. Segala kewangan dari awal hingga akhir kajian dan penulisan ditanggung oleh diri sendiri sebagai penulis.

\section{Konflik Kepentingan (Conflict of Interests)}

Penulis tidak mempunyai konflik kepentingan dalam penulisan artikel ini. Penulisan ini ditulis tanpa adanya konflik yang timbul.

\section{Rujukan}

Abdul Rashid et al. (2020). Strategi Pembangunan Aspek Kesejahteraan Kendiri Bagi Mendepani Tekanan Akademik Semasa Wabak COVID-19. Malaysian Journal of Social Sciences and Humanities (MJSSH), 5(12), 16-30.

Amna Emda. (2017). Kedudukan Motivasi Belajar Siswa Dalam Pembelajaran. Jurnal Lantanida, 5(2), 93-196.

Awang, H. (2016). Stres dalam kalangan pelajar PISMP semasa praktikum. Jurnal Penyelidikan Dedikasi, 11, 146-160.

Azlina Mohd Khir et.al. (2020). Sokongan Sosial, Penghargaan Kendiri dan Kemurungan Dalam Kalangan Mahasiswa di Universiti. Malaysian Journal of Social Sciences and Humanities (MJSSH), 5(11), 33-42.

Bruffaerts, R., Mortier, P., Kiekens, G., Auerback, R. P., Cuijpers, P., Demyttenaere, K., Green, J. G., Nock, M. K., \& Kessler, R. C. (2018). Mental health problems in college freshmen: Prevalence and academic functioning. Journal of Affective Disorders, 224, 97-103.

Ciaviano, R. E. S. (2008) Quality of friendship relationship and development tasks in adolescence. Cognition, Brain, Behavior, 12(2), 183-203.

Cody, C. (2014). Self-Motivation Quiz University Counseling and Consulting Services, University of Minnesota, Quick-Scoring Achievement Motivation Quiz.

Cohen. (1998). Types of stressors that increase susceptibility to the common cold in healthy adults. Health Psychology, 17, 214-223.

Costello, J., Pickens, L. M., \& Fenton, J. (2001). Social Support: A Matter Of Connections. Chicago, IL: Chapin Hall Center for Children at the University of Chicago.

Dasar Kesihatan Mental Negara (2014). Layout Buku: Layout 1 5/14/12 2:34 PM Page. Kementerian Kesihatan Malaysia.

Diani Mardiana Mat Zain, Amirah Zainun \& Farhana Abdul Razak. 2017. Tekanan Emosi Dalam Kalangan Pelajar Pintar. Jurnal Sultan Alauddin Sulaiman Shah, (1), 108-118

Durham Insight. (2014). All the Lonely People: Social Isolation And Loneliness In County Durham. https://www.durhaminsight.info/wp-content/uploads/2018/09/DirectorofHealth-Annual-Report-Loneliness-and-Social-Isolation.pdf

Firdaus. A. G. (2020 Mac 14). Impak Psikologi Akibat Wabak COVID-19. Astro Awani. http://www.astroawani.com/berita-malaysia/impak-psikologi-akibat-wabak-covid19- 233648 
Ganesan Y. Talwar P. Norsiah Fauzan Oon Y.B. (2018). A Study on Stress Level and Coping Strategies among Undergraduate Students. Journal of Cognitive Sciences and Human Development 3(2).

Ghazali Darusalam \& Sufean Hussin. (2018). Metodologi Penyelididkan Dalam Pendidikan Amalan dan Analisis Kajian. Edisi Kedua. Penerbit Universiti Malaya.

Habeeb, K. A. (2010). Prevalence of stressors among female medical students Taibah University. Journal of Taibah University Medical Sciences, 5(2), 110-119.

Hanna, E., Fettweis, X., \& Hall, R.J. (2018) Brief communication: Recent changes in summer Greenland blocking captured by none of the CMIP5 models. The Cryosphere, 12, 3287-3292.

Irma Mahad, Ugartini Magesvaran \& Intan Nur Syuhada Hamzah. (2020). Sikap Dan Motivasi Murid Sekolah Rendah Terhadap Pembelajaran Bahasa Melayu Dalam Talian Sepanjang Perintah Kawalan Pergerakan. Jurnal Pendidikan Bahasa Melayu Jpbm. 11(1), 16-28

Irshad, S., Saleem, S. A. D. I. A., \& Mahmood, Z. (2015). Coping strategies of university students: A validation study. Journal of Pakistan Psychiatric Society, 12(1), 8-13.

Krejcie, R.V. \& Morgan, D.W. (1970) Determining Sample Size for Research Activities. Educational and Psychological Measurement, 30, 607-610.

Lawten, M.P. (1991). A Multidimensional View Of Quality Of Life In Frail Elders. In J.E.J.C. Rowe .J.E. Lubben D.E. Deutchman (Eds), The Concept And Measure Quality Of Life In The Frail Elderly. Sandiego, CA: Academic Press.

Maryam Muhammad. (2016). Pengaruh Motivasi Dalam Pembelajaran. Lantanida Journal, $4(2)$.

Moawad, R.A. (2020). Online Learning during the COVID- 19 Pandemic and Academic Stress in University Students. Revista Romaneasca pentru Educatie Multidimensionala, 12(2).

Mohd Dahlan A. Malek \& Ida Shafinaz Mohamed Kamil. (2020). Kesejahteraan Psikologi dalam Kalangan Atlet sukan di Institusi Pengajian Tinggi. Jurnal Psikologi dan Kesihatan Sosial, (4), 26-32.

Mohd Izani M. Z. (2020, Mei 7). Pendidikan Tinggi di Malaysia Pasca COVID-19: Perubahan dalam Kesinambungan. Astro Awani. http://www.astroawani.com/beritamalaysia/pendidikan-tinggi-di-malaysia-pascacovid-19-perubahan-dalamkesinambungan-241929

Mohd Majid Konting. (2005). Kaedah penyelidikan pendidikan Edisi ke 7. Kuala Lumpur; Dewan Bahasa dan Pustaka.

Muhammad A. F. A. (2020). Wabak Covid-19 ; Mahasiswa Manja \& Kesihatan 49 Mental: Sejauh Mana Kebenarannya?. https://medium.com/@adibbtp/wabak-covid19mahasiswa-manja-kesihatan-mental-sejauh-mana-kebenarannya-63a748245469

Muhammad Wafi Ramli \& Sharifah Rohayah Sheikh Dawood. (2020) Faktor Tekanan Dalam Kalangan Pelajar Universiti Sains Malaysia: Satu Tinjauan Awal. e-BANGI: Jurnal Sains Sosial dan Kemanusiaan, 17 (7), 66-76.

Nik Mohd Rahimi Nik Yusoff (2004). Kemahiran mendengar bahasa Arab: Satu kajian di Sekolah Menengah Kerajaan Negeri. Tesis Ph.D, Universiti Kebangsaan Malaysia, Bangi.

Noraini Idris. (2010). Penyelidikan dalam pendidikan. Kuala Lumpur: McGraw Hill Education.

Noraini Mohd Sukor, Nur Saadah Mohamad Aun \& Ezarina Zakaria. (2019). Sokongan Sosial, Daya Tahan Dan Kesejahteraan Subjektif Remaja Di Institusi Perlindungan Jabatan Kebajikan Masyarakat. Journal of Social Sciences and Humanities, 16(9), 184198. 
Norhana Ahad, M. F. (2020). Analisis Faktor Tekanan Yang Mempengaruhi Pelajar Kolej Komuniti Negeri Johor Ketika Perintah Kawalan Pergerakan. Jurnal Dunia Pendidikan, 150-172.

Nur Syazana Abd Shukor \& Mohd Nasir Masroom. (2020). Gaya Pembelajaran dan Motivasi Dalam Kalangan Calon SPM Di Sebuah Sekolah Menengah Agama di Negeri Johor. Jurnal Kemanusiaan, 18(2), 77-90.

Nurul Hudani Md Nawi et al. (2017). Hubungan antara Sokongan Sosial dengan Kemurungan dalam kalangan Penagih Dadah. Jurnal Pembangunan Sosial, 20, 29-49.

Oemar Hamalik. (2002). Psikologi Belajar dan Mengajar. Bandung: Sinar Baru Algensindo.

Othman Mohamed. (2000). Prinsisp Psikoterapi dan pengurusan dalam kaunseling. Serdang: Penerbit Universiti Putra Malaysia.

Pintrich, P.R., \& DeGroot, E. (1990). Motivational and self-regulated learning components of classroom academic performance. Journal of Educational Psychology, 82, 33-40.

Ramachandiran, M., \& Dhanapal, S. (2018). Academic stress among university students: A quantitative study of generation y and z's perception. Pertanika Journal of Social Sciences \& Humanities, 26(3), 2115-2128

Ribeiro, I. J., Pereira, R., Freire, I. V., de Oliveira, B. G., Casotti, C. A., \& Boery, E. N. (2018). Stress and quality of life among university students: A systematic literature review. Health Professions Education, 4(2), 70-77.

Rusni. 2020. Pengaruh Motivasi Kerja, Kompensasi Dan Disiplin Terhadap Produktivitas Kerja Karyawan Pada Pt. Cipta Karya Aceh Di Kabupaten Bireuen. Jurnal Kebangsaan, 9(7), 52-54.

Ryff, C. D. (1989). Happiness Is Everything, Or Is It? Explorations on The Meaning of Psychological Well-Being. Journal of Personality and Social Psychology, 57, 10691081.

Salam, A. et al. (2013). Stress among Medical Students in Malaysia: A Systematic Review of Literatures. International Medical Journal, 20(6), 649-655.

Thawabieh, A. M., \& Qaisy, L. M. (2012). Assessing stress among university students. American International Journal of Contemporary Research, 2(2), 110-116.

Wenjuan, G., Siqing, P., \& Xinqiao, L. (2020). Gender differences in depression, anxiety, and stress among college students: A longitudinal study from China. Journal of Affective Disorders, 263, 292-300

Yikealo D. (2018) The Level of Stress among College Students: A Case in the College of Education, Eritrea Institute of Technology. Open Science Journal, 3(4).

Yuan Kong. (2009). A Brief Discussion on Motivation and Ways to Motivate Students in English Language Learning. International Education Studies, 2(2).

Zaiton Akilah Zainal (2020). Tahap Kesejahteraan Psikologi dan Kawalan Diri Pelajar yang Tinggal di Dalam Kampus dan Luar Kampus Universiti Malaysia Sabah Semasa Tempoh Perintah Kawalan Pergerakan. Sarjana Muda Psikologi (Pembangunan Belia Dan Komuniti) Fakulti Psikologi Dan Pendidikan Universiti Malaysia Sabah

Zarien Nurlieyana Aminuddin, Azhar Md. Sabil, Abdul Rasid Jamian (2019). Understanding of Lecturers' Verbal Interaction in Teaching of Malay Language at Institute of Teacher Education. International Journal of Academic Research in Progressive Education and Development, 8(4), 997-1003.

Zurko. (2011). Friendship During Adolescence: The Necessity for Qualitative Research of Close Relationships. Polish Journal of Applied Psychology, 9(1), 21-38. 